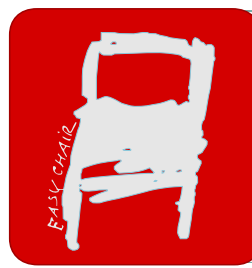

EPiC Series in Health Sciences

Volume 1, 2017, Pages 38-41

CAOS 2017. 17th Annual Meeting of the International

Society for Computer Assisted Orthopaedic Surgery

\title{
Intra-Operative Registration of 3D data capture with pre- operative plan for TKA
}

\author{
Benjamin Roberts $\mathrm{ME}^{1 *}$, Jason Hogan $\mathrm{BE}^{1}$, Elizabeth Kolos $\mathrm{PhD}^{1}$, Richard \\ Allom BSc (Hons) MSc, MBBS, FRCS (Tr\&Orth) ${ }^{2}$, Joshua Twiggs BE ${ }^{1}$, Brad \\ Miles $\mathrm{PhD}^{11 *}$ Corresponding Author/360 Knee Systems, Sydney, 2073, Australia, \\ Benjamin@kneesystems.com \\ ${ }^{2}$ North Sydney Orthopaedic and Sports Medicine Centre, The Mater Hospital, \\ North Sydney, 2060, Australia
}

\section{Introduction}

Total knee arthroplasty (TKA) is widely performed for improving pain and restoring function for patients with osteoarthritis (OA) and over 50000 primary procedures were performed in Australia in 2015 (Annual report 2016). Computer assisted pre-operative planning (CAPP) enhances accuracy of rotational and translational alignment of components (Schep 2003). It can be done with 3D bone surface modelling from CT or MRI scans and take kinematics and surgeon work flow into account. Computer assisted intra-operative navigation is also accessed by some surgeons and consists of three elements: software platform, point positions from reference arrays captured and reference device attached to the patient's bone (Bae 2011).

By incorporating CAPP with navigation, a correlation between the patient's anatomy from preoperative images can be established by gathering intra-operative anatomical landmarks and/or surface points and is known as registration (Chan 2016). However, identifying landmarks and acquiring images intra-operatively and the registration quality can be time-consuming and/or prone to risk. Customdesigned registration software that could reduce the time and error and be incorporated into the surgical workflow is needed (Chan 2016).

The aim of this study was to develop custom registration software using pre-operative planning and intra-operative 3D data capture and validate precision and repeatability using a preliminary Sawbones study. The repeatability of the process was verified by repeating over five sets of sawbones and the results are presented in Table 1 on page 3. 


\section{Materials and Methods}

A 3D scanner reference device was pinned on the Sawbone femur. The condyles and target block were then scanned. This 3D scan was filtered to remove extraneous bodies and noise leaving only the bony geometry and target block. The scanned geometry was then registered to the known bone geometry using a set of bony landmarks determined from CT. The entire registration process took two to three seconds to complete. A cutting block was then fixed to the reference device with the reference device attached visible to the camera. Pre-planned cut planes on a computer model of the bone were compared to the position and configuration of the distal cutting guide. Software guided the surgeon in realtime on the necessary configuration changes required to align the cutting block. The cut was performed on the distal femur by an experienced orthopedic surgical fellow. The cutting guide was then removed from the target-block and a second scan was performed. Filtering and registration were repeated and data was provided to the surgeon on precision of performed cut matching the plan. The process was the repeated a further four times to validate repeatability.

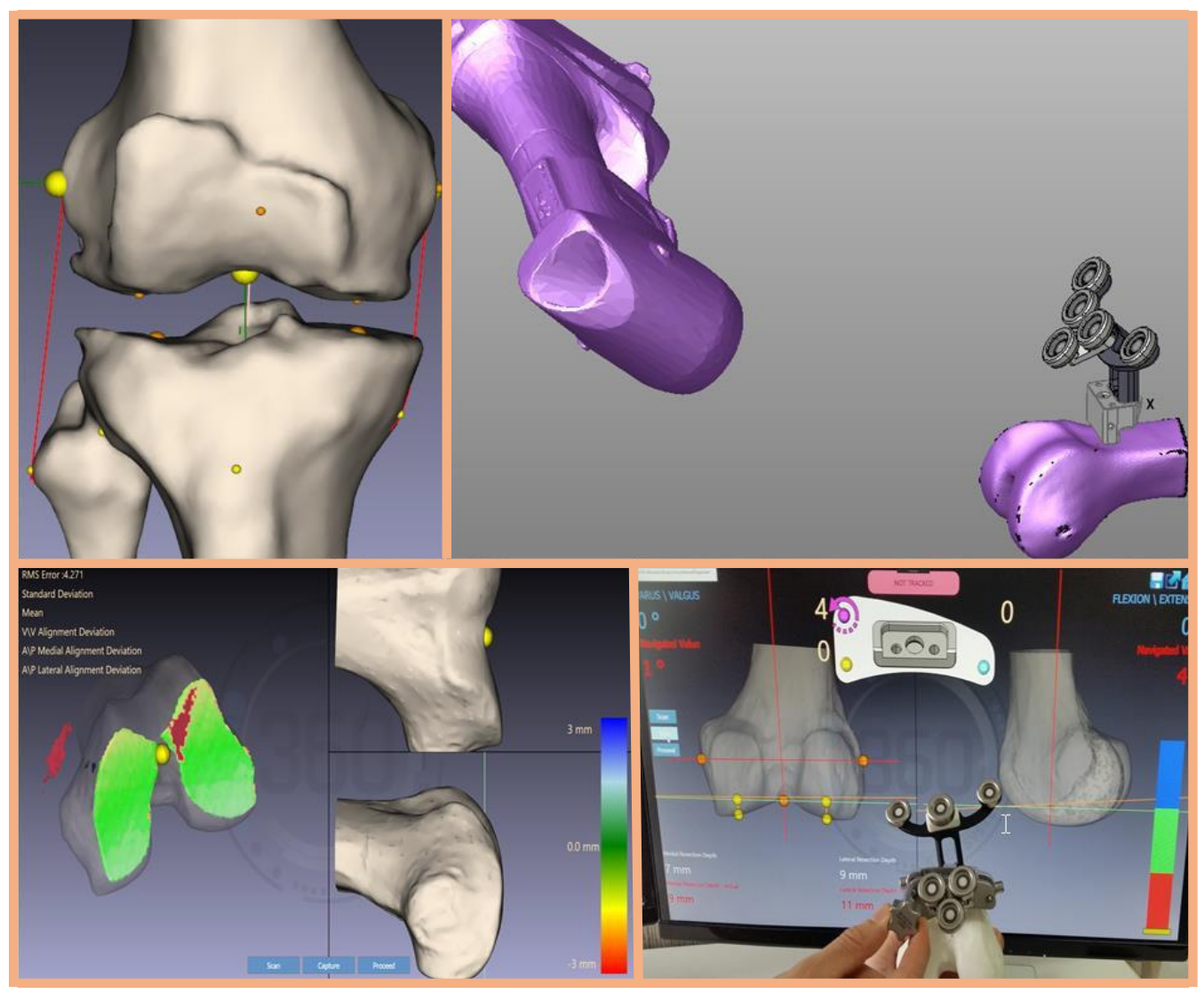

Figure 1: Top Left: A 3D model of the patient femur is landmarked by an engineer. Top Right: A 3D scanner scans the target array pinned onto the femur. Bottom Right: the software instructs the surgeon to position the cutting block at the correct plane. $B$ 


\section{Results}

\begin{tabular}{lcc|}
\hline \multicolumn{2}{l}{ Registration deviation } \\
\hline & Mean & SD \\
\hline Medial AP & -0.778 & 2.394 \\
\hline Lateral AP & -0.033 & 14.60 \\
& & 2 \\
\hline VV & 0.169 & 0.398 \\
RMS & 0.641 & 0.206 \\
\hline
\end{tabular}

\begin{tabular}{|c|c|c|c|c|c|c|}
\hline \multirow[t]{2}{*}{ Navigation } & \multicolumn{2}{|c|}{$\begin{array}{c}\text { Pre-pinning } \\
\text { of } \\
\text { distal } \\
\text { resection } \\
\text { block }\end{array}$} & \multicolumn{2}{|c|}{$\begin{array}{c}\text { Post pinning } \\
\text { of } \\
\text { distal } \\
\text { resection } \\
\text { block }\end{array}$} & \multicolumn{2}{|c|}{$\begin{array}{l}\text { Resection error } \\
\text { of } \\
\text { plane on } \\
\text { resected distal } \\
\text { femur }\end{array}$} \\
\hline & Mean & SD & Mean & SD & $\begin{array}{c}\text { Mea } \\
\mathrm{n}\end{array}$ & SD \\
\hline Flexion & -0.096 & $\begin{array}{c}0.49 \\
2\end{array}$ & -1.790 & $\begin{array}{c}0.42 \\
8\end{array}$ & $\begin{array}{c}- \\
1.59 \\
0\end{array}$ & $\begin{array}{c}1.02 \\
6\end{array}$ \\
\hline VV & 0.012 & $\begin{array}{c}0.28 \\
6\end{array}$ & -0.025 & $\begin{array}{c}0.41 \\
6\end{array}$ & $\begin{array}{c}0.14 \\
8\end{array}$ & $\begin{array}{c}0.39 \\
7\end{array}$ \\
\hline $\begin{array}{l}\text { Medial } \\
\text { resection } \\
\text { depth }\end{array}$ & 0.746 & $\begin{array}{c}0.80 \\
2\end{array}$ & 1.165 & $\begin{array}{c}0.19 \\
4\end{array}$ & $\begin{array}{c}1.60 \\
2\end{array}$ & $\begin{array}{c}0.67 \\
1\end{array}$ \\
\hline $\begin{array}{l}\text { Lateral } \\
\text { resection } \\
\text { depth }\end{array}$ & 0.644 & $\begin{array}{c}0.73 \\
3\end{array}$ & 0.853 & $\begin{array}{c}0.38 \\
4\end{array}$ & $\begin{array}{c}1.60 \\
6\end{array}$ & $\begin{array}{c}0.76 \\
5\end{array}$ \\
\hline
\end{tabular}

Figure 2 Table of mean and standard deviation for the set of five results: Anterior/Posterior (AP), VarusValgus (VV) Root Mean Square (RMS)

\section{Discussion}

The ability to obtain accurate and timely registration during surgery using preoperatively identified landmarks, alongside the small space requirements of a modern 3D scanner is sharply contrasted against the large space requirements and need for intraoperative probing of traditional navigation systems. This preliminary Sawbones study has clinical significance to validate software registration both before and after distal femur cut in a stable non-clinical environment. Resections were performed by an experienced Orthopedic surgeon. 
Results presented in Table 1 showed that the mean and standard deviation for registration on 5 Sawbones were small. Initial tracked values were small and limited error was introduced when the device was pinned. Root mean square (RMS) gives an indication of the quality of the fit between two meshes and is useful as a benchmark for minimal acceptable fit (in this case, an RMS less than one is desirable). After registration was completed, and the target cut plane achieved, the cutting block was pinned to increase rigidity. However, while VV values were largely unaffected by this, FE values increased postpinning. Results were comparable to similar studies (Chan 2016, Brin 2010) but have the advantage that the registration software is fast and can be operated intra-operatively. The software workflow accounts for surgical workflow and has less manual post-processing compared to a typical registration process.

Using CAPP eliminates potential errors caused by inaccurate selection of landmarks (Brin 2010). Even so, pre-CT scans did not capture the porosity of the Sawbones while the 3D scanner did and this had an effect on RMS values reported. Manual editing of the mesh to remove porosity from the 3D scanner images was required.

The purpose of this preliminary study was to validate the ability of the bespoke software to perform the registration process and validation of the workflow it entailed as a successful method of achieving the distal femoral cut. The experiments performed were designed to assess precision of registration that can be applied clinically. Thus, using 3D data capture intraoperatively and registering to a surgical plan based on CT scan could improve surgeon accuracy.

\section{References}

- Annual report for Hip and Knee Arthroplasty. Australian Orthopaedic Association, 2016

- Schep NW, Broeders IA, van der Werken C, Computer assisted orthopaedic and trauma surgery: State of the art and future perspectives, Injury, 34(4), pp. 299-306, 2003.

- Bae DK, Song SJ, Computer assisted navigation in knee arthroplasty, Clinics in Orthopedic surgery, 3(4), pp. 259-67, 2011

- Chan B, Auyeung J, Rudan JF, Ellis RE, Kunz M, Intraoperative application of hand- held structured light scanning: a feasibility study, International journal of computer assisted radiology and surgery, 11(6), pp 1101-1108, 2016.

- Brin YS, Livshetz I, Antoniou J, Greenberg - Dotan S, Zukor DJ, Precise landmarking in computer assisted total knee arthroplasty is critical to final alignment, Journal of Orthopaedic Research,28(10), pp 1355-1359, 2010.

\section{DISCLOSURES}

One or more authors are employed or consult to 360 Knee Systems, Sydney. 